\title{
COMPOSIÇÃO FLORÍSTICA E ANÁLISE FITOSSOCIOLÓGICA DO COMPONENTE ARBUSTIVO-ARBÓREO DE UM REMANESCENTE FLORESTAL NO AGRESTE PARAIBANO ${ }^{1}$
}

\author{
Israel Marinho Pereira ${ }^{2}$ \\ Leonaldo Alves de Andrade ${ }^{3}$ \\ Maria Regina de V. Barbosa ${ }^{4}$ \\ Everardo. V. S. B. Sampaio ${ }^{5}$
}

Recebido em 25/07/2001. Aceito em 20/03/2002.

\begin{abstract}
RESUMO - (Composição florística e análise fitossociológica do componente arbustivo-arbóreo de um remanescente florestal no Agreste Paraibano). O levantamento florístico e fitossociológico dos componentes arbóreoarbustivos, em uma área de floresta no agreste paraibano, foi feito utilizando-se 30 parcelas de $10 \times 20 \mathrm{~m}$, distribuídas por todo remanescente, e tomando-se os dados de altura total e diâmetro do caule ao nível do solo (DNS) de todos os indivíduos existentes nas parcelas, inclusive os mortos ainda de pé, com altura $\geq 1 \mathrm{~m}$ e DNS $\geq 3 \mathrm{~cm}$. Foram registrados 1952 indivíduos, pertencentes a 22 famílias, 38 gêneros e 54 espécies. As famílias de maior destaque, com relação ao número de espécies e indivíduos foram: Mimosaceae (6); Euphorbiaceae (6); Caesalpiniaceae (5) e Rubiaceae (5). A densidade total, área basal total, diâmetro máximo e altura máxima registrados foram 3253 indivíduos ha ${ }^{-1}, 34,77 \mathrm{~m}^{2} \mathrm{ha}^{-1}, 63 \mathrm{~cm}$. e $15 \mathrm{~m}$. Dos indivíduos amostrados, 45,7\% apresentaram diâmetro entre $3 \mathrm{e} 6 \mathrm{~cm}$. A espécie Thiloa glaucocarpa (Mart.) Eichl. apresentou o maior valor de IVI. Constatou-se que a área estudada apresentou composição florística variada, com presença de espécies comuns às caatingas e espécies características de outras formações mais úmidas como as florestas montanas dos brejos de altitude.
\end{abstract}

Palavras-chave - Fitossociologia, agreste, Paraíba, composição florística, floresta seca

\begin{abstract}
Floristic an phytosociological analysis of the woody vegetation in a forest remnant in the agreste region of Paraíba, Brazil.) A floristic and phytosociological survey was conducted in a caatinga area in the Agreste (sub-humid) region of Paraíba state. All trees and shrubs $\geq$ taller than $1 \mathrm{~m}$ and larger than $\geq 3 \mathrm{~cm}$ stem diameter found in 30 plots, 10x20m each, were identified and measured. Standing dead plants were also included. A total of 1952 plants were registered, belonging to 22 families, 38 genera and 54 species. Families with most species were Mimosaceae (6 species), Euphorbiaceae (6), Caesalpiniaceae (5), and Rubiaceae (5). Total plant density and stem basal area were 3253 plant ha ${ }^{-1}$ and $34.77 \mathrm{~m}^{2} \mathrm{ha}^{-1}$. Maximum diameter and height were $63 \mathrm{~cm}$ and $15 \mathrm{~m}$. About half of the plants $(45.7 \%$ ) had a stem diameter between 3 and $6 \mathrm{~cm}$. Thiloa glaucocarpa (Mart.) Eichl. was the most impor-
\end{abstract}

Este trabalho é parte da dissertação de mestrado do primeiro autor, apresentado ao Curso de Pós-Graduação em Produção Vegetal da Universidade Federal da Paraíba (Areia, 2000).

2 Mestre em Produção Vegetal, Rua Paulo Pontes, 153, Centenário. CEP: 58108-055 Campina Grande-PB.

e-mail: impereirapb@bol.com.br

Prof. Adjunto do Departamento de Fitotecnia- CCA,UFPB, CEP:58397-000 Areia-PB. e-mail:landrade@cca.ufpb.br

4 Departamento de Sistemática e Ecologia, CCEN, UFPB- Caixa Postal 5065, Cidade Universitária, CEP: 58051-970. João PessoaPB. E-mail: mregina@dse.ufpb.br

Departamento de Energia Nuclear-DEN-UFPE. Av. Prof. Luís Freire 1000, CEP: 50740-540 Recife-PE. e-mail: esampaio@npd.ufpe.br 
tant species (highest IVI value). The flora included mostly species already registered in other caatinga areas but also species which are typical from more mesic formations, specially the humid forests of high altitudes in Northeast Brazil.

Key words - Phytosociology, agreste, Paraíba, floristic composition, dry forests

\section{Introdução}

O agreste é uma microrregião do Nordeste Brasileiro que se caracteriza como área de transição entre a zona da mata e a zona das caatingas interioranas, com trechos quase tão úmidos como no litoral e outros secos como no sertão (Andrade, 1980; Andrade, 1989; Lins, 1989). O agreste estende-se do Rio Grande do Norte ao Sudeste da Bahia (Rizzini, 1979). Esta zona de transição no estado da Paraíba abrange áreas planas e superfícies elevadas da porção oriental do planalto da Borborema, onde se vê a transição entre os brejos úmidos e o sertão das caatingas (Pontes-Lins e Medeiros, 1994) e estende-se por cerca de $8.126 \mathrm{~km}^{2}$ (Duque, 1953). Ela pode ser dividida em agreste sublitorâneo que se desenvolve na depressão sublitorânea, e agreste da Borborema, nas áreas ocupadas por parte dos municípios de Areia, Campina Grande, Esperança, Montadas, Pocinhos, Puxinanã, Remígio, Fagundes e Queimadas, dentre outros (Duque, 1980).

A vegetação primitiva do agreste nordestino foi quase totalmente devastada e o solo foi intensamente ocupado pelas culturas agrícolas e pastagens. Há mais de 20 anos, as formações arbóreas já encontravam-se reduzidas a pequenos fragmentos isolados (Duque, 1980). Contudo, há indicativos que esta região tenha sido coberta por uma floresta tropical densa semelhante às chamadas matas secas. As ações antrópicas sistematizadas levaram ao desaparecimento quase que completo dessa cobertura vegetal, dando lugar a uma vegetação de xerofilismo mais acentuado, com características semelhantes às caatingas propriamente ditas (BOLETIM DE RECURSOS NATURAIS, 1963)

O conhecimento da flora e da vegetação do semi-árido tem sido bastante ampliado, tanto nas áreas da depressão sertaneja (Tavares et al., 1969a; 1970; 1974a; 1975; Albuquerque et al., 1982; Lyra, 1982; Santos et al., 1992; Hardesty, 1988; Rodal, 1992; Araújo et al., 1995; Ferraz et al., 1998), quanto nas áreas sedimentares (Emperaire, 1985; Oliveira et al., 1997; Araújo et al., 1998a; Araújo et al., 1998b; Rodal et al., 1998; Araújo \& Martins, 1999; Rodal et al., 1999). Por outro lado, pouco ou quase nada se sabe a respeito da vegetação que ocorre nas áreas de transição, particularmente no agreste.

A exploração perdulária dos recursos naturais e a devastação generalizada da cobertura vegetal nativa, vêm provocando impactos ambientais de grande magnitude, cujas conseqüências exigem intervenção imediata no sentido de amenizar os problemas daí decorrentes. Faz necessário assegurar a conservação de remanescentes representativos dos principais ecossistemas, bem como sustentabilidade dos sistemas produtivos neles inseridos (BRASIL, 1991). Diante da escassez de informações e do avançado grau de degradação em que se encontra a vegetação no agreste da Paraíba, o estudo dos remanescentes que ainda apresentam boas condições de conservação, são fundamentais ao planejamento de uso e à exploração sustentada do referido bioma.

O presente trabalho tem como objetivo contribuir para o conhecimento florístico e fitossociológico das matas de agreste, atra- 
vés do levantamento de um remanescente localizado no agreste paraibano.

\section{Material e métodos}

Caracterização da área - $\mathrm{O}$ estudo foi realizado em um remanescente de caatinga, com aproximadamente 60 ha, localizado na Fazenda São Bento, na fronteira dos Municípios de Areia e Remígio-PB (6 52' 52"'S e 35\%47'42”'W), com altitude em torno de e $596 \mathrm{~m}$. Situa-se na zona fisiográfica do agreste paraibano, caracterizada como área de transição ecológica entre a floresta montana (brejo de altitude) e a vegetação caducifólia espinhosa (caatinga). O solo predominante é classificado como Regossolo Distrófico, muito arenoso e raso, fase caatinga hipoxerófila zona da Borborema Ocidental, relevo suave ondulado e ondulado (BRASIL, 1971).

Os valores médios das determinações físicas e químicas de amostras de solo coletadas na área, na profundidade de $0-20 \mathrm{~cm}$ foram: densidade do solo e de partículas $=1,39$ e $2,62 \mathrm{~kg}$ $\mathrm{dm}^{-1}$; areia silte e argila $=725,122$ e $153 \mathrm{~g} . \mathrm{kg}^{-}$ ${ }^{1}$, respectivamente; $\mathrm{pH}$ em água $=4,7 ; \mathrm{P} \mathrm{e} \mathrm{K}=$ 3,6 e $129 \mathrm{mg} . \mathrm{dm}^{-3}$, respectivamente; $\mathrm{Al} \mathrm{e} \mathrm{Ca}+$ $\mathrm{Mg}=0,55$ e 3,7 Cmol.dm ${ }^{-3}$; e $\mathrm{MO}=170$ g.dm ${ }^{-3}$.

O clima é do tipo As' (quente e úmido) de Köppen, com pluviosidade média anual de aproximadamente $700 \mathrm{~mm}$, e déficit hídrico acentuado durante quatro a cinco meses (BRASIL, 1971).

Coleta e identificação do material botânico Foram realizadas coletas mensais da flora arbustivo-arbórea por toda a área, no período de 12 meses (janeiro/1999 a janeiro/2000). A identificação foi realizada, por comparações com exsicatas já identificadas depositadas nos herbários Jaime Coelho de Morais (EAN) e Lauro Xavier (JPB), ambos pertencentes à da Universidade Federal da Paraíba ou através de consultas à literatura especializada. O material coletado foi incorporado à coleção do herbário EAN.
Coleta e tratamento dos dados estruturais - o levantamento foi realizado adotando-se o método de parcelas (Mueller-Dumbois \& Ellenberg, 1974). Foram instaladas 30 unidades amostrais de $10 \times 20 \mathrm{~m}$., distribuídas aleatoriamente por toda a área. Nestas unidades foram amostrados todos os indivíduos, vivos ou mortos ainda em pé, que possuísse simultaneamente, diâmetro do caule ao nível do solo igual ou superior a $3 \mathrm{~cm}$ e altura total igual ou superior a $1 \mathrm{~m}$. Foram calculados os parâmetros gerais: densidade total, área basal total, alturas e diâmetros médios e máximos e os parâmetros relativos das espécies como densidade, freqüência, dominância e o índice de valor de importância (Martins, 1990; Rodal et al., 1992). A análise fitossociológica foi feita usando-se o pacote FITOPAC1 (Shepherd, 1995). Foram calculados também, o índice de riqueza de táxons (Whittaker, 1975) e o índice de diversidade de Shannon (Magurran, 1988).

\section{Resultados e discussão}

O processamento e a análise dos dados revelaram um conjunto florístico representado por 54 espécies, 38 gêneros e 22 famílias (Tabela 1). Das 22 famílias, 12 foram representadas por apenas uma espécie. As famílias com maior número de espécies foram Mimosaceae e Euphorbiaceae (6 espécies); Caesalpiniaceae e Rubiaceae (5) e Anacardiaceae e Myrtaceae (3). Essas seis famílias juntas respondem por mais de $50 \%$ do total das espécies amostradas. Cinco destas também foram destacadas por Alcoforado-Filho et al. (Aceito), em trabalho realizado no agreste de Pernambuco. Com exceção de Rubiaceae e Myrtaceae, as outras famílias correspondem àquelas de maior número de espécies em várias outras áreas da caatinga (Lyra, 1982; Emperaire, 1991; Fonseca, 1991; Horta et al., 1991; Ferraz, 1994; Araújo et al., 1995).

A ocorrência de Myrtaceae e Rubiaceae tem sido registrada no componente lenhoso, de 
Tabela 1. Espécies registradas em um remanescente de caatinga na fazenda São

\begin{tabular}{|c|c|c|c|}
\hline Família/Espécies & Nome vulgar & Hábito & $\mathrm{N}^{\mathrm{o}}$ da amostra \\
\hline \multicolumn{4}{|l|}{ Anacardiaceae } \\
\hline Myracrodruon urundeuva Allemão & Aroeira & Árvore & 27 \\
\hline Schinopsis brasiliensis Engl. & Braúna & Árvore & 29 \\
\hline Spondias tuberosa Arruda & Imbuzeiro & Árvore & 30 \\
\hline \multicolumn{4}{|l|}{ Apocynaceae } \\
\hline Aspidosperma pyrifolium Mart. & Pereiro & Árvore & 28 \\
\hline \multicolumn{4}{|l|}{ Bignoniaceae } \\
\hline Tabebuia impetiginosa (Mart. ex DC.) Standl. & Pau-d'arco roxo & Árvore & 32 \\
\hline Tabebuia serratifolia (Vahl.) G. Nichols. & Pau-d'arco amarelo & Árvore & 52 \\
\hline \multicolumn{4}{|l|}{ Bombacaceae } \\
\hline Ceiba glaziovii (Kuntze) K. Schum. & Barriguda & Árvore & 34 \\
\hline Pseudobombax marginatum (St. Hill.) A.Robyns & Embiratanha & Árvore & 35 \\
\hline \multicolumn{4}{|l|}{ Burseraceae } \\
\hline Commiphora leptophloeos (Mart.) J.B. Gillett. & Imburana de espinho & Árvore & 31 \\
\hline \multicolumn{4}{|l|}{ Cactaceae } \\
\hline Cereus jamacaru DC. & Mandacaru & Árvore & 36 \\
\hline Pilosocereus pachycladus subsp. & Facheiro & Árvore & 37 \\
\hline \multicolumn{4}{|l|}{ Pernambucensis (Ritter) Zappi } \\
\hline \multicolumn{4}{|l|}{ Caesalpiniaceae } \\
\hline Bauhinia cheilantha (Bong.) Steud. & Mororó & Árvore & 38 \\
\hline Caesalpinia ferrea Mart. ex Tul. & Pau ferro & Árvore & 40 \\
\hline Caesalpinia pyramidalis Tul. & Catingueira & Árvore & 39 \\
\hline Senna spectabilis (DC.) Irwin \& Barneby & Canafistula & Árvore & 41 \\
\hline Caesalpiniaceae 1 & Quebra faca & Arbusto & 45 \\
\hline \multicolumn{4}{|l|}{ Capparaceae } \\
\hline Capparis flexuosa (1.) L. & Feijão bravo & Árvore & 42 \\
\hline Capparis jacobinae Moric. ex Eichl. & Icó & Árvore & 43 \\
\hline \multicolumn{4}{|l|}{ Celastraceae } \\
\hline Maytenus rigida Mart. & Bom nome & Árvore & 44 \\
\hline \multicolumn{4}{|l|}{ Combretaceae } \\
\hline Thiloa glaucocarpa (Mart.) Eichl. & Sipaúba & Árvore & 3 \\
\hline \multicolumn{4}{|l|}{ Erythroxylaceae } \\
\hline Erythroxylum pauferrense T. Plowman & Coração de negro & Arbusto & 46 \\
\hline Erythroxylum sp. & Quiri preto & Arbusto & 49 \\
\hline \multicolumn{4}{|l|}{ Euphorbiaceae } \\
\hline Croton nepetaefolius Baill. & Pau leite & Arbusto & 15 \\
\hline Croton moritibensis Baill. & Velame & Arbusto & 13 \\
\hline Croton sonderianus Müll. Arg. & Marmeleiro & Arbusto & 7 \\
\hline Jatropha pohliana Müll. Arg. & Pinhão & Arbusto & 12 \\
\hline Manihot glaziovii Müll. Arg. & Maniçoba & Árvore & 6 \\
\hline Sapium sp. & Burra leiteira & Árvore & 5 \\
\hline Euphorbiaceae 1 & Café bravo & Arbusto & 48 \\
\hline
\end{tabular}


Tabela 1. continuação.

\begin{tabular}{|c|c|c|c|}
\hline Família/Espécies & Nome vulgar & Hábito & $\mathrm{N}^{\circ}$ da amostra \\
\hline \multicolumn{4}{|l|}{ Fabaceae } \\
\hline Amburana cearensis (Allemão) A.C. Smith & Cumarú & Árvore & 20 \\
\hline \multicolumn{4}{|l|}{ Mimosaceae } \\
\hline Acacia glomerosa Benth. & Espinheiro & Árvore & 14 \\
\hline Acacia sp. & Amorosa & Árvore & 16 \\
\hline Mimosa cf arenosa (Willd.) Poir. & Unha de gato & Arbusto & 51 \\
\hline Mimosa tenuiflora (Willd.) Poir. & Jurema preta & Árvore & 18 \\
\hline Piptadenia stipulacea (Benth.) Ducke & Jurema branca & Árvore & 17 \\
\hline Piptadenia viridiflora (Kunth) Benth. & Gicurí & Árvore & 21 \\
\hline \multicolumn{4}{|l|}{ Myrtaceae } \\
\hline Psidium albidum Cambess. & Cumati & Árvore & 23 \\
\hline Eugenia sp. & Mangaba brava & Árvore & 26 \\
\hline Eugenia uvalha Cambess. & Ubaia & Árvore & 33 \\
\hline \multicolumn{4}{|l|}{ Nyctaginaceae } \\
\hline Guapira sp. & João mole & Árvore & 4 \\
\hline \multicolumn{4}{|l|}{ Olacaceae } \\
\hline Ximenia americana $\mathrm{L}$. & Ameixa preta & Árvore & 25 \\
\hline Schoepfia brasiliensis DC. & Ameixa branca & Árvore & 24 \\
\hline \multicolumn{4}{|l|}{ Rhamnaceae } \\
\hline Ziziphus joazeiro Mart. & Juazeiro & Árvore & 22 \\
\hline \multicolumn{4}{|l|}{ Rubiaceae } \\
\hline Coutarea hexandra (Jacq.) K. Schum. & Quina - quina & Arbusto & 8 \\
\hline Guettarda sericea Müll. Arg. & Esporão de galo & Arbusto & 9 \\
\hline Randia nitida (HBK) DC. & Espinho de cruz & Arbusto & 10 \\
\hline Rubiaceae 1 & Desconhecida & Arbusto & 19 \\
\hline Tocoyena formosa (Cham. et Schltdl.) K. Schum. & Genipapo-bravo & Árvore & 11 \\
\hline \multicolumn{4}{|l|}{ Sapindaceae } \\
\hline Allophylus laevigatus (Turcz) Radlk. & Estraladeira & Arbusto & 2 \\
\hline \multicolumn{4}{|l|}{ Solanaceae } \\
\hline Cestrum cf. laevigatum Schltdl. & Gupuna & Arbusto & 1 \\
\hline \multicolumn{4}{|l|}{ Sterculiaceae } \\
\hline Helicteres eichleri K. Schum. & - & Arbusto & 53 \\
\hline Indeterminada 1 & - & Árvore & 54 \\
\hline Indeterminada 2 & Casca grossa & Árvore & 47 \\
\hline Indeterminada 3 & Sucupira & Árvore & 50 \\
\hline
\end{tabular}

outras áreas de caatinga, mas apenas nas de maior umidade como Caruaru-PE (Alcoforado Flho et al., Aceito), São José do Belmonte-PE (Tavares et al., 1969b) e Barbalha-CE (Tavares et al., 1974b). Já nas áreas de florestas montanas, como Pesqueira-PE (Correia, 1996) e Ja- taúba (Moura, 1997), é comum a presença de espécies pertencentes a essas famílias.

As famílias com maior número de indivíduos foram Mimosaceae com 369 (18,9\%), Combretaceae com 362 (18,6\%); Euphorbiaceae com $307(15,7 \%)$ e Caesalpiniaceae com 197 
(10\%). Juntas totalizaram $63 \%$ do total de indivíduos amostrados nesta fitocenose. Os elementos arbóreos mais conspícuos foram Aspidosperma pyrifolium Mart. (Apocynaceae), Caesalpinia pyramidalis Tul. (Caesalpiniaceae), Capparis jacobinae Moric. ex Eichl. (Capparaceae), Thiloa glaucocarpa (Mart.) Eichl. (Combretaceae), Croton sonderianus Müll. Arg. (Euphorbiaceae), Acacia sp e Piptadenia stipulacea (Benth.) Ducke (Mimosaceae), citados na maioria dos levantamentos realizados na vegetação caducifólia espinhosa e não espinhosa do nordeste brasileiro (Araújo et al., 1995; Araújo et al., 1998b; Ferraz et al., 1998; Alcoforado Filho et al., 1993). Além dessas espécies, registrou-se também a presença de Psidium albidum Cambess. (Myrtaceae), Guettarda sericea Müll. Arg., e Randia nitida (Kunth) DC. (Rubiaceae), táxons mais frequientes nas florestas montanas dos brejos de altitude. Isto ocorre provavelmente em decorrência da condição de maior umidade local. Tal comportamento também foi observado por Alcoforado-Filho et al. (Aceito) no agreste de Pernambuco.

O índice de riqueza taxonômica para espécies (RE) aqui encontrado foi de 6,73 sp/ln pl. Este valor é superior àqueles registrados nos pelos trabalhos realizados em áreas de vegetação caducifólia espinhosa, que variaram de 0,8 a 5,5 sp/ln pl, (Sampaio, 1996). Valor próximo ao encontrado neste trabalho foi registrado no agreste Pernambucano, no Município de Caruaru: 7,20 sp/ln pl (Alconforado-Filho, 1993). Porém, trabalhando com brejos de altitude no Estado da Paraíba Andrade et. al. (2001) obtiveram um RE de 7,49. Estes valores mostram que a riqueza de espécies expressa, em certa medida, o caráter de transição climática da área estudada, uma vez que situa-se entre aqueles registados para as áreas úmidas (brejos) e para as áreas de caatinga. Este parâmetro retrata, possivelmente, um dos aspectos que diferenciam a vegetação do agreste daquelas ocorrentes nos brejos úmidos e nas caatingas semi-áridas.
Em relação ao índice de diversidade de Shannon, o valor encontrado neste trabalho foi de 2,99 nats indivíduo ${ }^{-1}$. Este valor não difere substancialmente daqueles registrados para áreas de transição nos Estados de Pernambuco e Sergipe, bem como para o brejo de altitude do Estado da Paraíba 3,09, 3,06 e 3,0 nats indivíduo ${ }^{-1}$, respectivamente (Souza, 1983; Alconforado-Filho, 1993; Andrade et. al. 2001). Contudo, estes valores são superiores àqueles registrados em áreas de caatinga - 1,64 a 2,54 nats indivíduo ${ }^{-1}$ (Araújo et al., 1995; Lyra, 1982; Rodal et al., 1999; Ferraz et al. 1998). Os baixos índices de riqueza de espécies verificados nas áreas de caatinga devem estar associados, dentre outros fatores, às características bioclimáticas, do bioma e suas inter-relações (Araújo et al., 1995). O fato da área estudada localizar-se em ambiente de transição ecológica justifica a ocorrência de espécies típicas da caatinga e de espécies que são geralmente encontradas em formações mésicas. Esta característica contribuiu, para que o ambiente estudado apresentasse flora mais rica do que a maioria das áreas de caatinga avaliadas.

As alturas média e máxima do componente arbustivo-arbóreo foram de 4,8 e 15m, respectivamente. A maior densidade foi registrada na classe de 3 a 5 m de altura (Tab. 2). Em outros 11 levantamentos realizados em vegetação caducifólia espinhosa, apenas as áreas de maior disponibilidade hídrica, tiveram maior densidade nesta classe (Tab. 2). Já dois dos três levantamentos realizados em vegetação caducifólia não espinhosa e todos os realizados em florestas montanas apresentaram a maior densidade de indivíduos nesta classe (Tab. 2). As espécies arbóreas que mais se destacaram na paisagem devido ao porte exuberante foram: Schinopsis brasiliensis Engl., Myracrodruon urundeuva Allemão, Tabebuia impetiginosa (Mart. ex DC.) Standl., Ceiba glaziovii (Kuntze) K. Schum., Commiphora leptophloeos (Mart.) J.B. Gillett., Caesalpinia ferrea Mart. ex Tul., e Sapium sp. Dentre os levantamentos realizados em 
Tabela 2. Número de indivíduos por hectare e por classe de altura e diâmetro das plantas, em diferentes levantamentos no semi-árido nordestino

Vegetação Caducifólia Espinhosa

\begin{tabular}{|c|c|c|c|c|c|c|c|c|c|}
\hline \multirow[t]{2}{*}{ Local } & \multicolumn{4}{|c|}{ Classes de altura (m) } & \multicolumn{4}{|c|}{ Diâmetros $(\mathrm{cm})$} & \multirow[t]{2}{*}{ Referência } \\
\hline & $1-3$ & $>3-5$ & $>5-8$ & $>8$ & $3-12$ & $>12-27$ & $>27-42$ & $>42$ & \\
\hline Areia & 582 & 1658 & 897 & 117 & 2595 & 522 & 117 & 20 & Este trabalho \\
\hline Caruaru & 342 & 1816 & 1321 & 331 & 2802 & 305 & 66 & 3 & Alcoforado Filho 1993 \\
\hline Custódia & 1750 & 1034 & 955 & 238 & 2128 & 564 & 69 & 20 & Araújo et al 1995 \\
\hline Custódia & 684 & 608 & 368 & 212 & 1596 & 272 & 44 & 16 & Rodal 1992 \\
\hline Floresta & 788 & 584 & 448 & 56 & 1552 & 268 & 48 & 8 & Rodal 1992 \\
\hline Floresta & 972 & 808 & 364 & 28 & 1872 & 268 & 28 & 4 & Rodal 1992 \\
\hline Custódia & 372 & 272 & 164 & 268 & 748 & 176 & 68 & 88 & Rodal 1992 \\
\hline Serra Talhada & 1035 & 2030 & 41 & 85 & 2800 & 610 & 120 & 60 & Ferraz (1994) \\
\hline Serra Talhada & 170 & 2960 & 410 & 50 & 3025 & 410 & 115 & 5 & Ferraz (1994) \\
\hline Floresta & 2882 & 1925 & 578 & 0 & 3415 & 364 & 67 & 0 & Araújo et al 1995 \\
\hline Floresta & 2051 & 764 & 211 & 0 & 1763 & 319 & 46 & 15 & Araújo et al 1995 \\
\hline
\end{tabular}

Vegetação Caducifólia Não Espinhosa

\begin{tabular}{l|llllllll|l}
\hline P. Marcos & 2737 & 1369 & 505 & 9 & 4124 & 444 & 47 & 2 & Oliveira et al. (1997) \\
N. Oriente & 1044 & 2776 & 1148 & 4 & 5266 & 443 & 16 & 0 & Araújo et al.(1998a) \\
N. Oriente & 120 & 2284 & 2280 & 576 & 6325 & 272 & 4 & 0 & Araújo et al.(1998a) \\
N. Oriente & 132 & 2364 & 2484 & 528 & 5844 & 104 & 4 & 0 & Araújo et al.(1998a) \\
\hline
\end{tabular}

Floresta Montana

\begin{tabular}{l|cccccccc|c}
\hline Pesqueira & 1204 & 1467 & 864 & 1017 & 3417 & 834 & 247 & 47 & Correia (1996) \\
Triunfo & 655 & 3520 & 1990 & 370 & 2290 & 590 & 130 & 40 & Ferraz (1994) \\
Triunfo & 190 & 1470 & 890 & 510 & 5510 & 880 & 105 & 40 & Ferraz (1994) \\
\hline
\end{tabular}

caatinga, este foi o quinto colocado em número de indivíduos com altura superior a $8 \mathrm{~m}$. A maioria dos levantamentos em vegetação caducifólia não espinhosa e florestas montanas apresentaram maior número de indivíduos com altura superior a $8 \mathrm{~m}$ (Tab. 2).

O maior número de indivíduos foi constatado na classe de diâmetro de 3 a 12cm (2595 indivíduos $\mathrm{ha}^{-1}$ ), também verificado em outros levantamentos realizados em vegetação caducifólia espinhosa (Tab. 3). Houve uma tendência natural, nas diversas áreas observadas, de mai- or concentração de indivíduos nas menores classes de tamanho (Tab. 2). Segundo Bertoni (1984), a elevada concentração de indivíduos nas primeiras classes de diâmetro é comum e esperada, principalmente em vegetação onde está ocorrendo a regeneração natural das espécies.

Comparando-se a densidade de indivíduos com diâmetro superior a $12 \mathrm{~cm}$ (Tab. 2) com outras áreas de caatinga, verifica-se que a área estudada possui grande quantidade de indivíduos de maior porte . Isto proporcionou uma área basal total de $34,77 \mathrm{~m}^{2} \mathrm{ha}^{-1}$, superior aos valores 


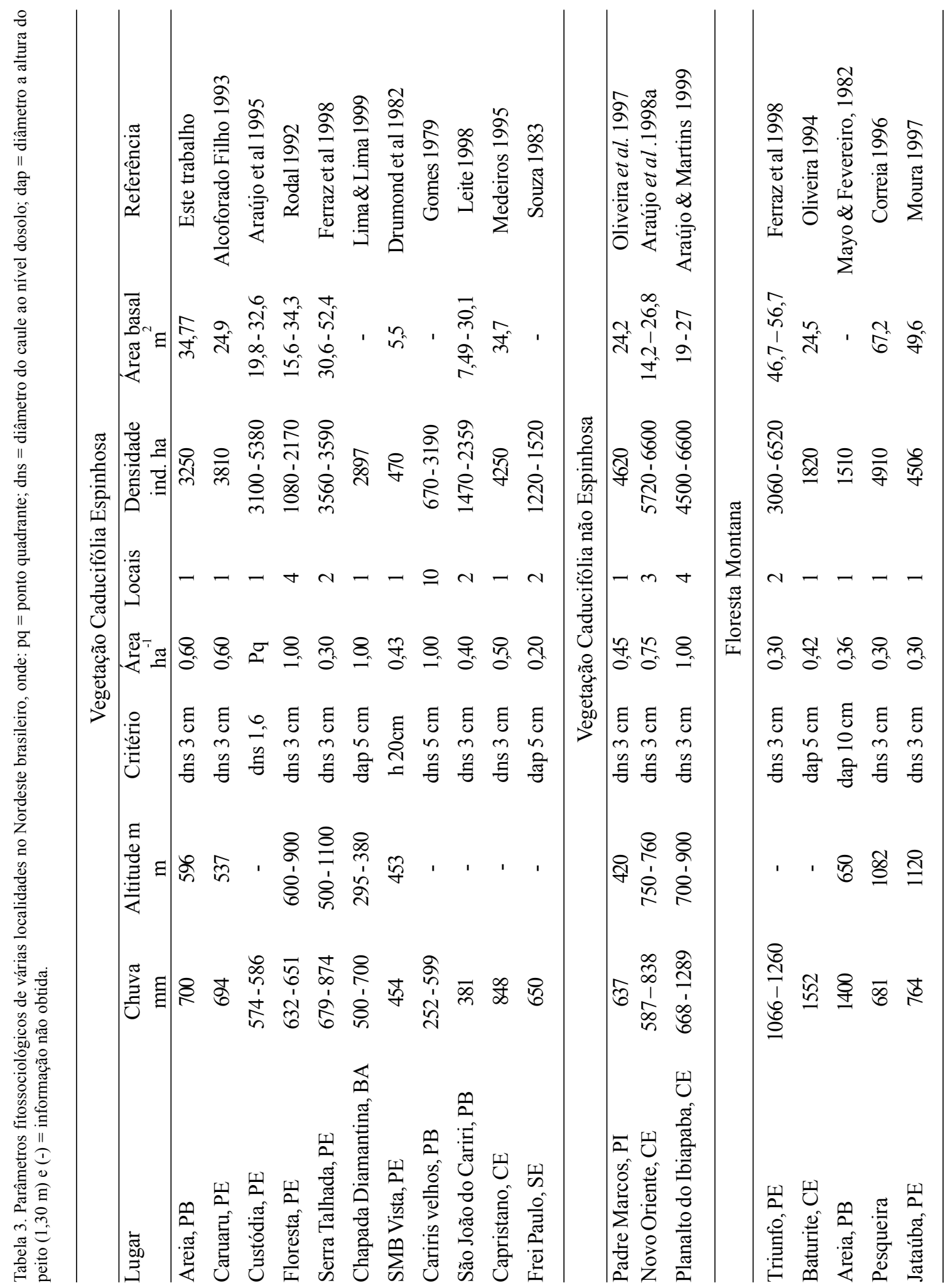


encontrados na maioria dos trabalhos realizados em área de caatinga (Tab. 3). As espécies que apresentaram as maiores áreas basais neste levantamento foram Commiphora leptophloeos, Schinopsis brasiliensis, Acacia sp., Caesalpinia pyramidalis, Aspidosperma pyrifolium e Thiloa glaucocarpa (Tab. 4). O conjunto dessas seis espécies teve uma área basal relativa de $56,4 \%$. As duas primeiras espécies destacam-se pelo porte dos indivíduos, o que lhes proporciona uma maior dominância, enquanto as demais são espécies de elevada densidade, o que justifica o valor aqui registrado.

Mesmo estando situada no agreste, uma zona considerada de transição entre o semi-árido e a mata úmida, a vegetação da área amostrada neste trabalho apresenta uma fisionomia semelhante à da maioria das áreas com vegetação caducifólia espinhosa. A densidade total calculada foi de 3253 indivíduos ha ${ }^{-1}$ e encontra-se entre as mais altas nas áreas de vegetação caducifólia espinhosa (Tab. 3). Em geral, o estabelecimento de limites mais amplos de inclusão de indivíduos em um levantamento, resulta em densidade maiores, ocorrendo o inverso quando se restringe esses limites. Incluindo-se apenas os indivíduos com diâmetro do caule ao nível do solo $\geq 3 \mathrm{~cm}$, têm-se obtido densidades variando de 2910 indivíduos ha-1 a 4250 indivíduos ha-1, para ambientes de caatinga (Sampaio,1996).

As cinco espécies que apresentaram os maiores índices de valor de importância (IVI) foram: Thiloa glaucocarpa, Acacia sp., Commiphora leptophloeos, Caesalpinia pyramidalis e Croton sonderianus. Juntas estas totalizam aproximadamente $40 \%$ do IVI total (Tab. 4). As espécies Thiloa glaucocarpa, Acacia sp., Commiphora leptophloeos, Caesalpinia pyramidalis, Croton sonderianus, Aspidosperma pyrifolium, Piptadenia stipulacea, Schinopsis brasiliensis, Sapium sp, e Guapira sp., destacaram-se das demais para o conjunto dos parâmetros analisados (Tab.4), sendo todas espécies registradas na maioria dos trabalhos rea- lizados em ecossistemas de caatinga (Sampaio, 1996).

As espécies Eugenia uvalha, Coutarea hexandra, Tabebuia impetiginosa e Tabebuia serratifolia (Tab. 4) são pouco freqüentes nos levantamentos na vegetação caducifólia espinhosa, sendo raramente encontradas em áreas de caatinga submetidas a maior semi-aridez. Observações regionais sugerem que estas espécies estariam circusnscritas às áreas de transição localizadas entre o litoral e o semi-árido, bem como às feições típicas do agreste nordestino.

Neste sentido, ressalta-se que não foi encontrado registro de ocorrência das espécies Erythroxylum pauferrense, Erythroxylum sp, Croton moritibensis, Psidium albidum, Helicteres eichleri, Tocoyena formosa e Allophylus laevigatus nos trabalhos realizados em áreas de caatinga, acessíveis aos autores. Algumas dessas espécies, porém, foram registradas em levantamento realizado em uma área de brejo de altitude, no Município de Areia-PB (Andrade et al., 2001), o que ratifica o caráter de transição da área estudada.

Entretanto, após comparar este remanescente com outras formações ocorrentes no Nordeste brasileiro, conclui-se que a área estudada enquadra-se melhor como vegetação caducifólia espinhosa (caatinga hipoxerófila), uma vez que aí fora registrado um maior número de famílias e espécies típicas dessa formação o que pode diferenciá-la das florestas montanas, dos brejos de altitude e da vegetação caducifólia não espinhosa (carrasco) do Nordeste.

\section{Referências Bibliográficas}

Albuquerque, S. G.; Soares, J. G. G.; Araújo Filho, J. A. 1982. Densidade de espécies arbustivas em vegetação de caatinga. Petrolina, EMBRAPA-CPATSA. (Pesquisa em andamento, 16).

Alcoforado Filho, F.G. Composição florística e fitossociológica de uma área de caatinga arbórea no Município de Caruaru-PE. Recife: 1993. 241p. Dissertação (Mestrado) Universidade Federal Rural de Pernambuco. 
Tabela 4 - Espécies amostradas e seus parâmetros fitossociológicos em uma área de caatinga no agreste paraibano, ordenados decrescentemente pelo IVI. DA= Densidade Absoluta (indivíduos ha $\left.{ }^{-1}\right)$; FA= Freqüência Absoluta (\%); $\mathrm{ABA}=$ Área Basal Absoluta $\left(\mathrm{m}^{2} \mathrm{ha}^{-1}\right) ; \mathrm{DR}=$ Densidade Relativa $(\%) ; \mathrm{FR}=$ Freqüência Relativa $(\%)$; ABR = Área Basal Relativa (\%); IVI = Índice de Valor de Importância (\%)

\begin{tabular}{|c|c|c|c|c|c|c|c|}
\hline Espécies & $\mathrm{DA}$ & FA & $\mathrm{ABA}$ & $\mathrm{DR}$ & FR & $\mathrm{ABR}$ & IVI \\
\hline Thiloa glaucocarpa & 567 & 100 & 2,466 & 17,42 & 6,11 & 7,09 & 30,62 \\
\hline Acacia sp. & 330 & 90 & 2,998 & 10,14 & 5,5 & 8,62 & 24,27 \\
\hline Commiphora leptophloeos & 100 & 76,67 & 5,433 & 3,07 & 4,68 & 15,63 & 23,38 \\
\hline Caesalpinia pyramidalis & 218 & 93,33 & 2,797 & 6,71 & 5,7 & 8,04 & 20,46 \\
\hline Croton sonderianus & 358 & 86,67 & 1,343 & 11,01 & 5,3 & 3,86 & 20,17 \\
\hline Aspidosperma pyrifolium & 197 & 76,67 & 2,525 & 6,05 & 4,68 & 7,26 & 17,99 \\
\hline Piptadenia stipulacea & 253 & 93,33 & 1,09 & 7,79 & 5,7 & 3,14 & 16,63 \\
\hline Schinopsis brasiliensis & 47 & 50 & 3,412 & 1,43 & 3,05 & 9,82 & 14,3 \\
\hline Sapium sp. & 92 & 66,67 & 1,845 & 2,82 & 4,07 & 5,31 & 12,2 \\
\hline Morta & 142 & 73,33 & 0,98 & 4,35 & 4,48 & 2,82 & 11,65 \\
\hline Guapira sp. & 113 & 83,33 & 0,964 & 3,48 & 5,09 & 2,77 & 11,35 \\
\hline Capparis jacobinae & 145 & 86,67 & 0,393 & 4,46 & 5,3 & 1,13 & 10,88 \\
\hline Tabebuia impetiginosa & 92 & 46,67 & 0,631 & 2,82 & 2,85 & 1,81 & 7,48 \\
\hline Cestrum cf. laevigatum & 89 & 70 & 0,324 & 2,05 & 4,28 & 0,93 & 7,26 \\
\hline Caesalpiniaceae 1 & 50 & 33,33 & 0,612 & 1,54 & 2,04 & 1,76 & 5,34 \\
\hline Amburana cearensis & 20 & 20 & 0,874 & 1,38 & 1,22 & 2,51 & 5,12 \\
\hline Pilosocereus pachycladus & 33 & 40 & 0,568 & 1,02 & 2,44 & 1,63 & 5,1 \\
\hline Manihot glaziovii & 48 & 33,33 & 0,314 & 1,49 & 2,04 & 0,9 & 4,43 \\
\hline Maytenus rigida & 25 & 10 & 0,982 & 0,77 & 0,61 & 2,83 & 4,2 \\
\hline Bauhinia cheilantha & 43 & 26,67 & 0,22 & 1,33 & 1,63 & 0,63 & 3,59 \\
\hline Acacia glomerosa & 27 & 36,67 & 0,123 & 0,82 & 2,24 & 0,35 & 3,41 \\
\hline Eugenia uvalha & 27 & 26,67 & 0,25 & 0,82 & 1,63 & 0,72 & 3,17 \\
\hline Allophylus laevigatus & 22 & 33,33 & 0,158 & 0,87 & 2,04 & 0,46 & 3,16 \\
\hline Capparis flexuosa & 25 & 30 & 0,093 & 0,77 & 1,83 & 0,27 & 2,87 \\
\hline Ceiba glaziovii & 7 & 13,33 & 0,635 & 0,2 & 0,81 & 1,83 & 2,85 \\
\hline Spondias tuberosa & 8 & 13,33 & 0,572 & 0,26 & 0,81 & 1,65 & 2,72 \\
\hline Myracrodruon urundeuva & 12 & 20 & 0,312 & 0,36 & 1,22 & 0,9 & 2,48 \\
\hline Indeterminada 1 & 8 & 16,67 & 0,331 & 0,26 & 1,02 & 0,95 & 2,23 \\
\hline Indeterminada 2 & 28 & 10 & 0,226 & 0,87 & 0,61 & 0,65 & 2,13 \\
\hline Erythroxylum pauferrense & 17 & 20 & 0,035 & 0,57 & 1,22 & 0,1 & 1,83 \\
\hline Indeterminada 3 & 5 & 6,67 & 0,371 & 0,15 & 0,41 & 1,07 & 1,63 \\
\hline Rubiaceae 1 & 10 & 10 & 0,183 & 0,31 & 0,61 & 0,53 & 1,44 \\
\hline Caesalpinia ferrea & 10 & 13,33 & 0,11 & 0,31 & 0,81 & 0,32 & 1,44 \\
\hline Guettarda sericea & 12 & 10 & 0,123 & 0,36 & 0,61 & 0,35 & 1,32 \\
\hline Psidium albidum & 10 & 13,33 & 0,06 & 0,31 & 0,81 & 0,17 & 1,3 \\
\hline Jatropha pohliana & 10 & 13,33 & 0,022 & 0,31 & 0,81 & 0,06 & 1,19 \\
\hline Cereus jamacaru & 7 & 10 & 0,063 & 0,2 & 0,61 & 0,18 & 1 \\
\hline
\end{tabular}


Tabela 4. Continuação.

\begin{tabular}{lccccccc}
\hline Espécies & DA & FA & ABA & DR & FR & ABR & IVI \\
\hline Indeterminada 4 & 7 & 10 & 0,037 & 0,2 & 0,61 & 0,11 & 0,92 \\
Piptadenia viridiflora & 3 & 6,67 & 0,127 & 0,1 & 0,41 & 0,36 & 0,87 \\
Coutarea hexandra & 7 & 10 & 0,013 & 0,2 & 0,61 & 0,04 & 0,85 \\
Ziziphus joazeiro & 5 & 10 & 0,019 & 0,15 & 0,61 & 0,05 & 0,82 \\
Randia nitida & 5 & 10 & 0,004 & 0,15 & 0,61 & 0,01 & 0,78 \\
Senna spectabilis & 3 & 6,67 & 0,061 & 0,1 & 0,41 & 0,18 & 0,68 \\
Mimosa tenuiflora & 3 & 6,67 & 0,021 & 0,1 & 0,41 & 0,06 & 0,57 \\
Ximenia americana & 3 & 6,67 & 0,021 & 0,1 & 0,41 & 0,06 & 0,57 \\
Schoepfia brasiliensis & 2 & 3,33 & 0,011 & 0,05 & 0,2 & 0,03 & 0,29 \\
Mimosa arenosa & 2 & 3,33 & 0,005 & 0,05 & 0,2 & 0,02 & 0,27 \\
Croton nepetaefolius & 2 & 3,33 & 0,004 & 0,05 & 0,2 & 0,01 & 0,26 \\
Pseudobombax marginatum & 2 & 3,33 & 0,003 & 0,05 & 0,2 & 0,01 & 0,26 \\
Indeterminada 5 & 2 & 3,33 & 0,003 & 0,05 & 0,2 & 0,01 & 0,26 \\
\hline Total & 3253 & 1636 & 34,77 & 100 & 100 & 100 & 300 \\
\hline
\end{tabular}

Alcoforado-Filho, F. G.; Sampaio, E. V. S. B.; Rodal, M. J. N. (Aceito). Florística e fitossociologia de um remanescente de vegetação caducifólia espinhosa arbórea em Caruaru, Pernambuco. Acta Botanica Brasilica.

Andrade, L. A.; Barbosa, M. R. V.; Sampaio, E. V. S. B.; Bruno, R. L. A. Estudo da Ecologia de Matas Ciliares Ocorrentes na Reserva Ecológica "Mata do Pau-Ferro", no Município de Areia, Estado da Paraíba: levantamento florístico, análise da estrutura fitossociológica do estrato arbóreo e da regeneração natural e ecofisiologia de sementes. UFPB/CCA-Areia. CNPq/PNEPG. 2001. 151p. (Relatório de Pesquisa).

Andrade, M. C. de. 1989. Ecossistemas e potencialidades dos recursos naturais do Nordeste. Recife: SUDENE/UFPE, v. 2. 348P.

Andrade, M. C. de. 1980. A terra e o homem no Nordeste. São Paulo: Ciências Humanas.

Araújo, E. L.; Sampaio, E. V. S. B.; Rodal, M. J. N. 1995. Composição florística e fitossociológica de três áreas de Caatinga de Pernambuco. Revista Brasileira de Biologia 55(4): 595-607.

Araújo, F. S.; Martins, F. R. 1999. Variações estruturais e florísticas do Carrasco no planalto da Ibiapaba, estado do Ceará. São Paulo, Acta Botanica Brasilica $13(1): 1-14$

Araújo, F. S.; Sampaio, E.V.S.B.; Rodal, M.J.N.; Fi- gueiredo, M.A. 1998a. Organização comunitária do componente lenhoso de três áreas de carrasco em Novo Oriente-CE. Revista Brasileira de Biologia 58 (1): 85-95.

Araújo, F. S.; Sampaio, E. V. S. B.; Figueiredo, M. A.; Rodal, M. J. N.; Fernandes, A. G. 1998b. Composição florística da vegetação de carrasco, Novo Oriente-CE. Revista Brasileira de Botânica. 21(2):15-26.

BOLETIM DE RECURSOS NATURAIS. 1963. RECIFE, SUDENE. v. 6, n. 1/4. p. 60-63.

BRASIL. Ministério do Meio Ambiente. 1991. O desafio do desenvolvimento sustentado: Relatório do Brasil para a Conferência das Nações Unidas Sobre o Meio Ambiente e Desenvolvimento. Brasília: p101-103.

BRASIL. 1971, Ministério da Agricultura. Equipe de pedologia e fertilidade do solo. Divisão de Agrologia - SUDENE. Levantamento exploratório. Reconhecimento de solos do Estado da Paraíba. Rio de Janeiro: 670p. (Boletim técnico, 15).

Bertoni, J. E. A. 1984. Composição florística e estrutura de uma floresta do interior do Estado de São Paulo: Reserva Estadual de Porto Ferreira. Campinas: 195p. Dissertação (Mestrado) Universidade Estadual de Campinas.

Correia, M. S. 1996. Estrutura da vegetação da mata serrana em um brejo de altitude em Pesqueira- 
PE: Recife: 89p. Dissertação (Mestrado) Universidade Federal de Pernambuco.

Drumond, M. A.; Lima, P. C. F.; Souza, S. M.; Lima, J. L. S. 1982. Sociabilidade das espécies florestais da caatinga em Santa Maria da Boa Vista-PE. Boletim de Pesquisa Florestal. Curitiba: n.4, p. 47-59.

Duque, G. 1980. O Nordeste e as lavouras xerófilas. 3 ed. Mossoró-RN: Fundação Guimarães Duque, 316p. (Coleção Mossoroense, 143). Duque, J. G. 1953. Solo e água no polígono das secas. Fortaleza: DNOCS, 220P.

Emperaire, L. 1991.Vegetação e flora. IN IBAMA, Plano de manejo do Parque Nacional da Serra da Capivara, São Raimundo Nonato - PI. Brasília : FUDAM. p. 61-206.

Emperaire, L. 1985. Végétation de l'État du Piaui, Brésil. Societé de Biogéographie 60(4):151-163.

Ferraz, E. M. N.; Rodal, M. J. N.; Sampaio, E. V. S. B.; Pereira, R. C. A. 1998. Composição florística em trechos de vegetação de caatinga e brejo de altitude na região do Vale do Pajeú, Pernambuco. Revista Brasileira de Botânica 21(1): 7-15.

Ferraz, E. M. N. 1994. Variação florística - vegetacional na Região do Pajeú, Pernambuco. Recife: 197p. Dissertação (Mestrado) Universidade Federal Rural de Pernambuco.

Fonseca, M. R, 1991. Análise da vegetação arbustivo-arbórea da caatinga hiperxerófila do Nordeste do Estado de Sergipe. Campinas: 187p. Tese (Doutorado) Universidade Estadual de Campinas.

Gomes, M. A. F. 1979. Padrões de caatingas nos cariris velhos da Paraíba. Recife: Universidade Federal Rural de Pernambuco. Dissertação de Mestrado.

Horta, M. B.; Costa, E.; Silva, L.V.; Pequeno, P. H. A. 1991. Estudos fitossociológicos no distrito de irrigação do Jaíba - Manga (MG). In: Del Rey Serviços de Engenharia Ltda. Vegetação e manejo de solos do distrito de irrigação do Jaíba. Belo Horizonte: p. 44-76 (Relatório).

Hardesty, L .H.; Box, T.W.; Malechek, J. C. 1988. Season of cutting affects biomass production by coppicing browse species of the Brazilian caatinga. Journal of Range Management, Denver, v.41, n.6, p.477-480.

Leite, U. T. 1998. Análise da estrutura fitossociológica do estrato arbustivo-arbóreo de duas tipologias de caatinga ocorrentes no Município de São João do Cariri - PB. Areia: Universidade Federal da Paraíba. Monografia de Graduação.

Lima, P. C. F. \& Lima, J. L. S. 1998. Composição Florística e fitossociologia de uma área de caatin- ga em Contendas do Simporá- Bahia, Microrregião homogênea da Chapada Diamantina. Acta botânica brasílica. 12 (3): 441-450.

Lins, R. C. 1989. As áreas de exceção do agreste de Pernambuco. Recife: SUDENE/PSU/SER, 402p. (SUDENE, Estudos Regionais, 20).

Lyra, A. L. R. T. 1982. A condição de "brejo"; efeito do relevo na vegetação de duas áreas do Município do Brejo de Madre de Deus - PE. Recife: 105p. Dissertação (Mestrado) Universidade Federal Rural de Pernambuco.

Magurran, A. E. 1988. Ecological diversity and its measurement. New Jersey: Princeton University.

Martins, F. R. 1990. Atributos de comunidades vegetais. Quid. 9:13-17.

Mayo, S. J. \& Fevereiro, U. P. B. 1982. Mata do PauFerro. A pilot study of the brejo Forest of Paraíba, Brazil. London: RoyalBotanic Gardens, Kew.

Medeiros, J. B. L. P. 1995. Florística e fitossociologia de uma área de caatinga localizada na Fazenda Aracanga, Município de Capristano-CE. Fortaleza: Trabalho de conclusão de curso (Graduação). Universidade Federal do Ceará.

Moura, F. de B. P. 1997. Fitossociologia de uma mata serrana semidecídua no brejo de Jataúba, Pernambuco, Brasil. Recife. dissertação (Mestrado) Universidade Federal de Pernambuco.

Mueller -Dumbois, D \& Ellenberg, H. 1974. Aims and methods of vegetation ecology. New York: John Wiley \& Sons.

Oliveira, M. E. A.; Sampaio, E. V. S. B.; Castro, A. A. J. F.; Rodal, M. J. N. 1997. Flora e fitossociologia de uma área de transição carrasco-caatinga de areia em Padre Marcos, Piauí. Naturalia 22:131-150.

Oliveira, M. R. L. 1994. Composição florística e análise fitossociológica de uma área de mata úmida na Serra do Baturité - CE. Fortaleza: Universidade Federal do Ceará - Monografia de Graduação.

Pontes-Lins, J. R. \& Medeiros, A. N. 1994 Mapeamento da cobertura florestal nativa lenhosa do Estado da Paraíba. João Pessoa: PNUD/FAO/IBAMA/ GOVERNO DA PARAÍBA. 44p.

Rizzini, C. T. 1997. Tratado de fitogeografia do Brasil: aspectos sociológicos e florístico. v. 2 São Paulo: HUCITEC, EDUSP.

Rodal, M. J. N. 1992. Fitossociologia da vegetação arbustivo-arbórea em quatro áreas de caatinga em Pernambuco. Campinas. 198p. Tese (Doutorado) Universidade Estadual de Campinas.

Rodal, M.J.N.; Andrade, K.V. de S.A.; Sales, M.F. de, Gomes, A.P.S. 1998. Fitossociologia do compo- 
nente lenhoso de um refúgio vegetacional no município de Buíque, Pernambuco. Revista Brasileira de Biologia 58 (3):517-526.

Rodal, M. J. N.; Nascimento, L. M.; Melo, A. L. 1999. Composição florística de um trecho de vegetação arbustiva caducifólia, no município de Ibimirim, Pernambuco, Brasil.. Acta Botanica Brasilica 13 (1): 14-29.

Rodal, M. J. N.; Sampaio, E. V. S.; Figueiredo, M. A. 1992. Manual sobre métodos de estudo florístico e fitossociológico - ecossistema caatinga. Brasília: Sociedade Botânica do Brasil. 24p.

Sampaio, E. V. S. B. 1996. Fitossociologia. p 203-230. In: Sampaio, E. V. S. B.; Mayo S. J.; Barbosa, M. R. V. (eds.) Pesquisa botânica nordestina: progresso e perspectivas. Sociedade Botânica do Brasil/Seção Regional de Pernambuco. Recife.

Santos, M. F. A. V.; Ribeiro, M. R.; Sampaio, E. V. S. B. 1992. Semelhanças vegetacionais em sete solos de caatinga. Pesquisa Agropecuária Brasileira 27: 305-314.

Shepherd, G. J. 1995. FITOPAC 1. Manual do usuário. Departamento de Botânica. Campinas: UNICAMP.

Souza, G. V. 1983. Estrutura da vegetação da caatinga hipoxerofila do Estado de Sergipe. Recife: 95p. Dissertação (Mestrado) Universidade Federal Rural de Pernambuco.

Tavares, S.; Paiva, F. A. V.; Tavares, E. J. S.; Carvalho, G. H. \& Lima, J. L. S. 1969a. Inventário florestal do Ceará. 1. Estudo preliminar das matas remanescen- tes do município de Quixadá. Boletim de Recursos Naturais 7(1/4): 93-111.

Tavares, S.; Paiva, F. A. V.; Tavares, E. J. S.; Lima, J. L. S. \& Carvalho, G. H. 1969b. Inventário florestal de Pernambuco. Estudo preliminar das matas remanescentes do município de São José do Belmonte. Boletim de Recursos Naturais 7(1/4):113-139.

Tavares, S.; Paiva, F. A. V.; Tavares, E. J. S.; Carvalho, G. H. \& Lima, J. L. S. 1970. Inventário florestal de Pernambuco. Estudo preliminar das matas remanescentes do município de Ouricuri, Bodocó, Santa Maria da Boa Vista e Petrolina. Boletim de Recursos Naturais 8(1/2):149-194.

Tavares, S.; Paiva, F. A. V.; Tavares, E. J. S. \& Lima, J. L. S. 1974a. Inventário florestal do Ceará II. Estudo preliminar das matas remanescentes do município de Tauá. Boletim de Recursos Naturais 12(2):5-19.

Tavares, S.; Paiva, F. A. V.; Tavares, E. J. S. \& Lima, J. L. S.. 1974b. Inventário florestal do Ceará III. Estudo preliminar das matas remanescentes do município de Barbalha. Boletim de Recursos Naturais 12(2):20-46.

Tavares, S.; Paiva, F. A. V.; Tavares, E. J. S. \& Carvalho, G .H. 1975. Inventário florestal da Paraíba e no Rio Grande do Norte 1. Estudo preliminar das matas remanescentes do vale do Piranhas. Recife. SUDENE. (Recursos Naturais, 3).

Whittaker, R. H. Communities and ecosystems. New York, MacMillan, 1975p. 